This is an electronic reprint of the original article. This reprint may differ from the original in pagination and typographic detail.

\author{
Author(s): Leppänen, Marja; Henriksson, Pontus; Nyström, Christine Delisle; Henriksson, Hanna; \\ Ortega, Francisco B.; Pomeroy, Jeremy; Ruiz, Jonatan R.; Cadenas-Sanchez, Cristina; \\ Löf, Marie
}

Title: $\quad$ Longitudinal Physical Activity, Body Composition, and Physical Fitness in Preschoolers

Year: $\quad 2017$

Version:

Please cite the original version:

Leppänen, M., Henriksson, P., Nyström, C. D., Henriksson, H., Ortega, F. B., Pomeroy, J., Ruiz, J. R., Cadenas-Sanchez, C., \& Löf, M. (2017). Longitudinal Physical Activity, Body Composition, and Physical Fitness in Preschoolers. Medicine and Science in Sports and Exercise, 49(10), 2078-2085.

https://doi.org/10.1249/MSS.0000000000001313

All material supplied via JYX is protected by copyright and other intellectual property rights, and duplication or sale of all or part of any of the repository collections is not permitted, except that material may be duplicated by you for your research use or educational purposes in electronic or print form. You must obtain permission for any other use. Electronic or print copies may not be offered, whether for sale or otherwise to anyone who is not an authorised user. 


\section{Medicine \& Science \\ IN \\ Sports \& Exercise}

The Official Journal of the American College of Sports Medicine www.acsm-msse.org

... Published ahead of Print

\section{Longitudinal Physical Activity, Body Composition, and Physical Fitness in Preschoolers}

Marja H Leppänen ${ }^{1}$, Pontus Henriksson ${ }^{2,3}$, Christine Delisle Nyström ${ }^{4}$, Hanna Henriksson ${ }^{2,3}$, Francisco B Ortega ${ }^{3}$, Jeremy Pomeroy ${ }^{5}$, Jonatan R Ruiz ${ }^{3}$,

Cristina Cadenas-Sanchez ${ }^{3}$, and Marie Löf ${ }^{2,4}$

${ }^{1}$ Faculty of Sport and Health Sciences, University of Jyvaskyla, Jyvaskyla, Finland; ${ }^{2}$ Department of Clinical and Experimental Medicine, Faculty of Health Science, Linkoping University, Linkoping, Sweden; ${ }^{3}$ PROmoting FITness and Health through physical activity research group (PROFITH), Department of Physical Education and Sports, Faculty of Sport Sciences, University of Granada, Spain; ${ }^{4}$ Department of Biosciences and Nutrition, Karolinska Institutet, NOVUM, Huddinge, Sweden; ${ }^{5}$ Marshfield Clinic Research Foundation, Marshfield, WI

Accepted for Publication: 1 May 2017

Medicine \& Science in Sports \& Exercise ${ }_{\circledast}$ Published ahead of Print contains articles in unedited manuscript form that have been peer reviewed and accepted for publication. This manuscript will undergo copyediting, page composition, and review of the resulting proof before it is published in its final form. Please note that during the production process errors may be discovered that could affect the content. 


\title{
Longitudinal Physical Activity, Body Composition, and Physical Fitness in
}

\section{Preschoolers}

\author{
Marja H Leppänen ${ }^{1}$, Pontus Henriksson ${ }^{2,3}$, Christine Delisle Nyström ${ }^{4}$, \\ Hanna Henriksson ${ }^{2,3}$, Francisco B Ortega ${ }^{3}$, Jeremy Pomeroy ${ }^{5}$, Jonatan R Ruiz ${ }^{3}$, \\ Cristina Cadenas-Sanchez ${ }^{3}$, and Marie Löf ${ }^{2,4}$
}

${ }^{1}$ Faculty of Sport and Health Sciences, University of Jyvaskyla, Jyvaskyla, Finland; ${ }^{2}$ Department of Clinical and Experimental Medicine, Faculty of Health Science, Linkoping University, Linkoping, Sweden; ${ }^{3}$ PROmoting FITness and Health through physical activity research group (PROFITH), Department of Physical Education and Sports, Faculty of Sport Sciences, University of Granada, Spain; ${ }^{4}$ Department of Biosciences and Nutrition, Karolinska Institutet, NOVUM, Huddinge, Sweden; ${ }^{5}$ Marshfield Clinic Research Foundation, Marshfield, WI

Correspondence: Marja Leppänen, University of Jyvaskyla, P.O. Box 35, FI-40014 University of Jyvaskyla, Finland, Email: marja.h.leppanen@student.jyu.fi

Running head: Longitudinal physical activity in children

Trial registration: clinical trial (https://clinicaltrials.gov/: NCT02021786). 
The results of the present study do not constitute endorsement by ACSM, and the results are presented clearly, honestly, and without fabrication, falsification, or inappropriate data manipulation. The MINISTOP project was funded by the Swedish Research Council (project no. 2012-2883, ML), the Swedish Research Council for Health, Working Life and Welfare (20120906, ML), Bo and Vera Axson Johnsons Foundation and Karolinska Institutet (ML). MHL was supported by a grant from Juho Vainio Foundation and from University of Jyvaskyla; PH was supported by a grant from Henning and Johan Throne-Holst Foundation; CDN was supported by a grant from the Swedish Nutrition Foundation; HH was supported by grants from the Swedish Society of Medicine and the County Council of Östergötland, Sweden; FBO and CC-S were supported by the Spanish Ministry of Economy and Competitiveness (grants RYC-2011-09011 and BES-2014-068829, respectively). None of the authors had a conflict of interest. 


\section{ABSTRACT}

Purpose: To investigate longitudinal associations of objectively-measured physical activity (PA) and sedentary behavior (SB) with body composition and physical fitness at a 12-month followup in healthy Swedish 4-year-old children. Methods: The data from the population-based MINISTOP trial were collected between 2014-2016, and this study included the 138 children who were in the control group. PA and SB were assessed using the wrist-worn ActiGraph (wGT3x-BT) accelerometer during seven 24-hour periods, and subsequently, defined as SB, light-intensity PA (LPA), moderate-intensity PA (MPA), vigorous-intensity PA (VPA), and moderate-to-vigorous PA (MVPA). Body composition was measured using air-displacement plethysmography, and physical fitness (cardiorespiratory fitness, lower and upper muscular strength as well as motor fitness) by the PREFIT fitness battery. Linear regression and isotemporal substitution models were applied. Results: Greater VPA and MVPA at the age of 4.5 were associated with higher fat-free mass index (FFMI) at 5.5 years of age $(\mathrm{p}<0.001$ and $\mathrm{p}=0.044$, respectively). Furthermore, greater VPA and MVPA at the age of 4.5 were associated with higher scores for cardiorespiratory fitness, lower body muscular strength and motor fitness at 12-month follow-up ( $\mathrm{p}=0.001$ to $\mathrm{p}=0.031$ ). Substituting 5 -minutes/day of SB, LPA or MPA for VPA at the age of 4.5 were associated with higher FFMI, and with greater upper and lower muscular strength at 12-month follow-up ( $\mathrm{p}<0.001$ to $\mathrm{p}=0.046)$. Conclusion: Higher VPA and MVPA at the age of 4.5 were significantly associated with higher FFMI and better physical fitness at 12-month follow-up. Our results indicate that promoting high intensity PA at young ages may have long-term beneficial effects on childhood body composition and physical fitness, in particular muscular strength. Keywords: exercise, sedentary behavior, obesity, cardiorespiratory fitness, muscular strength, pediatrics 


\section{INTRODUCTION}

Childhood obesity is a growing public health problem all over the world (40), and it has been associated with many physical and psychological consequences, such as metabolic risk factors and decreased health-related quality of life (32). Overweight and obesity have been found to progress from early childhood to adolescence $(26,33)$, and due to their influence on energy balance, increasing knowledge of associations between physical activity (PA) and sedentary behavior (SB) with adiposity already in young children is needed. Our recent cross-sectional study in 4.5-year-olds (22) found a strong positive relationship between vigorous-intensity PA (VPA) and fat-free mass index (FFMI), while moderate-to-vigorous PA (MVPA) was negatively associated with fat mass percent (\%FM). Similar findings have also been reported in other crosssectional studies in preschool aged children $(3,4,9,10,20,38)$, but the relationship between SB and adiposity is still inconsistent $(4,9,10,14,20,22)$. However, only a few studies in preschoolers have examined longitudinal associations between PA and adiposity, reporting negative associations $(19,25)$, and no association $(3,24)$ as well as a positive association between SB and body mass index (BMI) (19). These studies have utilized subjective measurement of PA and SB (19) as well as BMI $(19,24)$ or bioimpendance (3) in estimating body fatness, which may not be an accurate measurement in children $(12,16)$. Thus, further longitudinal studies using objective and accurate measurements of PA, SB and body composition in preschoolers are needed in order to investigate whether PA and/or SB is longitudinally associated with body composition. Such knowledge may help health care professionals target actions for obesity prevention already at young ages. 
Physical fitness has been recognized as an important marker of health $(29,30,34)$. Previous cross-sectional studies $(3,22)$ have reported that PA was positively associated with physical fitness in preschoolers, while a higher amount of self-reported PA has also been associated with better motor fitness (1). However, to our knowledge, there are no previous studies examining longitudinal associations of SB with physical fitness, and only one study has investigated the longitudinal associations of PA with limited components of physical fitness in preschool aged children (3).

Hence, the aim of this study was to investigate the longitudinal associations of PA and SB with body composition and physical fitness in healthy Swedish children at 4.5 years of age and 12 months later as a follow-up from our previous cross-sectional study (22). As an additional aim, we also studied whether a change in PA and SB between 4.5 and 5.5 years of age was associated with corresponding change in body composition and physical fitness.

\section{SUBJECTS AND METHODS}

\section{Study design and participants}

The present study utilized baseline and 12-month follow-up data from the MINISTOP trial collected between 2014-2016, and the details of the trial have been described previously by Delisle et al. (11). Briefly, MINISTOP was a two-arm, parallel design randomized controlled and population-based trial in 315 healthy Swedish 4-year-old children. The 6-month intervention consisted of a mobile phone-based application (the MINISTOP app) to help parents promote healthy eating and PA in children. The outcomes of the trial have been previously published (13). 
Participants were recruited from the population register at Statistics of Sweden. Invitation letters $(n=3368)$ were sent in the spring of 2014 to the guardians (parents and other caretakers) of all 4year-old children living in the county of Östergötland, asking them to participate in the study. Parents were included in to the study if they had a healthy 4-year-old child, had the possibility to have their child measured at baseline (approximately at 4.5 years of age), and for at least one parent to able to speak and read Swedish sufficiently well. In total, 315 completed the baseline measures and were enrolled in the intervention study. Children in the control group $(n=159)$, i.e. those who did not receive any intervention, were included in this study. Those with insufficient accelerometer data at baseline $(\mathrm{n}=8)$ or lack of anthropometric measurements at follow-up $(n=13)$ were excluded from the analyses. In total, 138 children were included in the analyses for this study. Informed consent, witnessed and formally recorded, was obtained from all parents. The trial was registered at clinicaltrials.gov (NCT02021786) and approved by the Research Ethics Committee, Stockholm, Sweden (2013/1607-31/5; 2013/2250-32).

\section{Data collection}

The children's PA, SB, body composition and physical fitness were measured at the hospital in the same way at baseline and again after 12 months. PA and SB were assessed using the wristworn ActiGraph wGT3x-BT triaxial accelerometer (www.actigraphcorp.com), and children were asked to wear the accelerometer for $24 \mathrm{~h}$ over 7 consecutive days. The monitors were set to sample at $50 \mathrm{~Hz}$. Since the PA levels in our 138 children were similar on both week and weekend days (data not shown), children with at least 3 days of valid activity data, regardless of the day of the week, were included in the analyses. A valid day was defined as $\geq 600 \mathrm{~min}$ of awake wearing time (10). Non-wearing time was determined according to van Hees et al. (39), 
and the time scored as worn was classified into sleep or awake time using the Sadeh algorithm $(35,36)$. ActiLife software (version 6.11.2) was used to process the raw data to derive filtered sum of vector magnitudes (VM) in 10-s epochs. The time spent (minutes/day) in intensityspecific PA levels and in SB were calculated for each child. The cut-points were defined for SB as VM $\leq 305$; for light-intensity PA (LPA), as VM 306-817; for moderate-intensity PA (MPA), as VM 818-1968; for VPA, as VM $\geq 1969$; and for MVPA, as VM $\geq 818$ in accordance with Chandler et al. (7).

Height and waist circumference were measured using standardized procedures as previously described (5). Body composition was assessed using air-displacement plethysmography by means of the pediatric option for BodPod (www.cosmed.com) (15). The body composition measures included were BMI, fat mass index (FMI), fat-free mass index (FFMI) and fat mass percent $(\% \mathrm{FM})$. BMI was calculated as body weight $(\mathrm{kg}) / \mathrm{height}^{2}(\mathrm{~m})$, FMI as fat mass $(\mathrm{kg}) /$ height $^{2}(\mathrm{~m})$, and FFMI as fat-free mass $(\mathrm{kg}) /$ height $^{2}(\mathrm{~m})$.

Physical fitness was measured using four tests within the PREFIT fitness test battery (28): a $20 \mathrm{~m}$ shuttle run test for cardiorespiratory fitness, a handgrip strength test for upper body muscular strength, a standing long jump test for lower body muscular strength, and a 4 x $10 \mathrm{~m}$ shuttle run test for motor fitness (speed/agility). The tests were applied twice, except the $20 \mathrm{~m}$ shuttle run test which was conducted once. Regarding handgrip strength test, the best value of the two attempts for each hand was selected, and the average of both hands was used in the analyses. For the standing long jump and the $4 \times 10 \mathrm{~m}$ shuttle run tests, the best values of the two attempts were used in the analysis. The PREFIT test battery is based on a systematic review about the reliability and validity of physical fitness tests in preschool children (28), and it has been 
recognized as a feasible tool in assessing physical fitness in preschool aged children (6). The details of the measurements of PA, SB, body composition and physical fitness have been previously published $(5,22)$. In addition, parents reported their age, body weight, height and education by means of a questionnaire.

\section{Statistical methods}

For this analysis, we considered that a sample size of 133 provides $80 \%$ power (two-tailed and $\alpha=0.05$ ) to detect a standardized regression coefficient of 0.24 . Descriptive information is given as arithmetic means (SD) or frequencies (percentages). Linear regression was used to assess the association between intensity-specific PA (LPA, MPA, VPA and MVPA) and SB at baseline with body composition measurements and physical fitness tests at the 12-month follow-up. At first, we fitted unadjusted models and, subsequently, each model was adjusted for child's sex (boy or girl) and age (continuous) at the measurement and ActiGraph awake wearing time (continuous) due to potential effect on body composition and physical fitness. The models with SB, LPA or MPA as exposures were also adjusted for VPA, while models with VPA or MVPA were adjusted for SB. In addition, we fitted isotemporal substitution models (23) to estimate the effect of substituting one PA type with another PA type at baseline on body composition or physical fitness at the 12-month follow-up. In supplemental analyses, we examined the associations of change in intensity-specific PA and SB with change in body composition and physical fitness between baseline and the 12-month follow-up. The change values for each variable were calculated as the 12-month follow-up value subtracted by the corresponding baseline value. In sensitivity analyses, we additionally adjusted the regression models for maternal BMI (continuous), maternal educational attainment (university degree or no university 
degree), paternal BMI (continuous), paternal educational attainment (university degree or no university degree). Since the results were similar (data not shown), these variables were not included in the final adjusted models.

Sex comparisons between average values were made by using independent t-test for continuous variables, and chi-square test for categorized variables. We also investigated if the associations differed by sex by adding an interaction term (type of PA $\mathrm{x}$ child's sex) to the adjusted regression models. For these analyses, we considered $\mathrm{p}<0.01$ as the level of significance for the interaction terms to control for multiple comparisons. We did not find any evidence for any sex interactions, and consequently, we present the results for boys and girls together.

Control of regression models showed that required assumptions (independence, linearity, homoscedasticity and normality) were not violated. All statistical tests were conducted using the two sided 5\% level of significance and performed using SPSS Statistics 24 (IBM, Armonk, NY, USA).

\section{RESULTS}

\section{Background characteristics}

The average age of the participating children's mothers $(n=138)$ at baseline was 35 years (SD 4.3), height $167 \mathrm{~cm}$ (SD 0.1), weight $67 \mathrm{~kg}$ (SD 11.9), BMI $23.8 \mathrm{~kg} / \mathrm{m}^{2}$ (SD 4.1), and more than half of them $(n=95,68.8 \%)$ had a university degree. The fathers $(n=136)$ average age was 38

years (SD 5.1), height $182 \mathrm{~cm}$ (SD 0.1), weight $84 \mathrm{~kg}$ (SD 13.0), BMI $25.4 \mathrm{~kg} / \mathrm{m}^{2}$ (SD 3.5), and more than half of them $(n=76,55.1 \%)$ had a university degree. 
Table 1 describes the characteristics of the 138 children at baseline and at the 12-month followup, and is sub-divided by sex. Valid accelerometer data for the children were obtained for 3 (2.0\%), 4 (2.9\%), 5 (6.5\%), $6(13.0 \%)$ and 7 (75.4\%) days at baseline.

\section{Associations of PA and SB at baseline with body composition at 12-month follow-up}

Table 2 presents the associations of intensity-specific PA and SB at baseline with body composition at the 12-month follow-up. Greater VPA was associated with higher BMI $(p=0.005)$, which was due to higher FFMI $(p<0.001)$ and not FMI $(p=0.79)$. Furthermore, greater MVPA was associated with higher FFMI ( $\mathrm{p}=0.044)$. No significant relationships between SB, LPA (data not shown) or MPA with FMI or \%FM were discovered.

Isotemporal substitution analyses (Figure 1) showed that substituting 5-minutes/day of SB, LPA or MPA with 5-minutes/day of VPA at the age of 4.5 was related to higher FFMI at 5.5 years of age $(\mathrm{p}<0.001$ to $\mathrm{p}=0.001)$ as well as to higher $\mathrm{BMI}(\mathrm{p}=0.003$ to $\mathrm{p}=0.006)$. In contrast, we found no statistically significant associations for FMI or \%FM when substituting any of the PAs (data not shown).

\section{Associations of PA and SB at baseline with physical fitness at 12-month follow-up}

Cardiorespiratory fitness: Greater VPA and/or MVPA were associated with more laps in the $20 \mathrm{~m}$ shuttle run test $(\mathrm{p}=0.016$ and $\mathrm{p}=0.014)$ (Table 2$)$. However, as shown in Figure 1 , when substituting any of the PAs, there were no statistically significant associations observed. Upper muscular strength: Before adjusting for confounders, greater VPA was associated with better handgrip strength score $(\mathrm{p}=0.002)$. However, after adjustments, the association disappeared 
$(\mathrm{p}=0.083)$. Yet, substituting 5-minutes/day of SB, LPA or MPA with 5-minutes/day of VPA at the age of 4.5 were related to better handgrip strength at 5.5 years of age $(p=0.026$ to $p=0.046)$ (Figure 1). Lower muscular strength: Greater VPA or MVPA were associated with longer jumps in the standing long jump test, respectively $(\mathrm{p}=0.001$ and $\mathrm{p}=0.023)$ (Table 2$)$. When substituting 5-minutes/day of SB, LPA or MPA with 5-minutes/day of VPA at the age of 4.5 were associated with longer jumps at 5.5 years of age, respectively $(\mathrm{p}=0.002$ to $\mathrm{p}=0.014)$ (Figure 1$)$. Motor fitness: Greater VPA and MVPA were associated with faster time in the 4 x 10 m shuttle run test $(\mathrm{p}=0.031$ and $\mathrm{p}=0.026$, respectively) (Table 2). As presented in Figure 1, when substituting any of the PAs, there were no statistically significant relationships observed.

\section{Associations of change in PA and SB between baseline and 12-month follow-up with change in body composition and physical fitness}

Additionally, we examined associations of change in PA and SB between baseline and 12-month follow-up with the corresponding change in body composition and physical fitness as shown in Supplemental Table 1 (see Table, Supplemental Digital Content 1, Associations of change in accelerometer-derived physical activity intensities (per 5-min change) with change in body composition and physical fitness between baseline at 4.5 years of age and the 12 -month followup, http://links.lww.com/MSS/A952). When adjusting for confounders, increases in VPA over the follow-up period was associated with decrease in \%FM and FMI ( $\mathrm{p}=0.004$ and $\mathrm{p}=0.048)$ as well as improved upper and lower muscular strength ( $\mathrm{p}=0.030$ and $\mathrm{p}=0.033$, respectively). Furthermore, an increase in MVPA was associated with an increase in FFMI $(\mathrm{p}=0.037)$ and a decrease in $\% \mathrm{FM}(\mathrm{p}=0.031)$. 


\section{DISCUSSION}

Our main finding is that higher VPA and MVPA at the age of 4.5 were associated with higher FFMI and better physical fitness at the 12-month follow-up. Furthermore, substituting 5minutes/day of SB, LPA, or MPA with VPA at 4.5 years were associated with higher FFMI, and greater upper and lower muscular strength at follow-up. The results support our hypothesis that high-intensity PA is longitudinally associated with a healthier body composition and better physical fitness.

We found that greater VPA or MVPA at the age of 4.5 were associated with higher FFMI at 5.5 years of age. The finding is in line with our cross-sectional study (22), but additionally, fills the current knowledge gap about the longitudinal association between PA and FFMI in young children. Since the previous studies $(3,19,24,25)$ have not measured associations of PA with FFMI, our findings are novel. One important finding is that greater VPA at the age of 4.5 was positively associated with BMI at 5.5 years of age. Due to the detailed body composition measurement, we were able to divide body weight into fat-free mass and fat mass. Since VPA in this study was associated with higher FFMI, but not FMI, we can conclude that the association between VPA and BMI was actually reflecting an association between VPA and FFMI. Previous studies $(3,19,24)$ have examined longitudinal associations between PA and change in BMI, finding negative associations (19) as well as no association $(3,24)$. However, the different study designs as well as methods in assessing PA and body composition may have led to the somewhat contradictory results. Thus, future studies should preferably include detailed body composition measurements, and not just BMI, together with objective measurements of PA. We did not find any significant associations between intensity-specific PA at the age of 4.5 and \%FM or FMI at 
5.5 years of age, which is in line with Bürgi et al. (3). It is possible that young children's nature of being active, short bursts of high level PA and varying intervals of different intensities, may not always be enough in reducing \%FM. Indeed, low levels of PA have been related to higher subcutaneous fat by means of skinfolds (25), however, the skinfold technique has been found to be a less accurate method to assess body composition in preschoolers (18).

No statistically significant association between SB at the age of 4.5 and body composition measurements at 5.5 years of age were found. Jago et al. (19) has previously reported that SB, based on a direct observation, was positively associated with change in BMI. Due to the limitations concerning observation method (2), further studies are needed to investigate the longitudinal association between objectively measured SB and body composition, and to clarify what amounts of SB increases the risk of unhealthier body composition.

Greater VPA and MVPA at the age of 4.5 were significantly related to cardiorespiratory fitness at 5.5 years of age. To our knowledge, only Bürgi et al. (3) have previously studied the association between baseline PA and change in cardiorespiratory fitness over a 9-month followup reporting a positively significant result. Our results confirm their findings, and additionally expand the literature by providing data on muscular strength. In addition, we observed that substituting 5-minutes/day of LPA for VPA at the age of 4.5 was associated with a better score in the $20 \mathrm{~m}$ shuttle run test at 5.5 years of age. However, the result did not quite reach the significance $(\mathrm{p}=0.056)$, but the tendency supports our hypothesis that high-intensity PA instead of light-intensity PA may also improve cardiorespiratory fitness in preschoolers. In addition, we observed that VPA or MVPA at the age of 4.5 was significantly related to better scores in lower muscular strength and motor fitness at 5.5 years of age. This result is expected, since the 
association between VPA and lower muscular strength was also very strong in our crosssectional study (22). However, the longitudinal design brings a novel contribution to the existing literature. We found that substituting 5-minutes/day of SB, LPA or MPA for VPA at the age of 4.5 was associated with better score in handgrip strength test at 5.5 years of age, which highlights the possible role of VPA instead of lighter PA in improving upper muscular strength. The results support our interpretation that the positive association between VPA and MVPA with BMI reflected higher fat-free mass instead of fat mass, given the strong association of FFMI with physical fitness in preschoolers (17). Bürgi et al. (3) has previously reported a positive association between baseline VPA and change in agility over 9-month follow-up. Thus, it seems reasonable to conclude that VPA and MVPA may predict later motor fitness in preschool aged children. Furthermore, there was a trend $(\mathrm{p}=0.091)$ that substituting 5 -minutes/day of LPA for VPA at the age of 4.5 was related to a better score in motor fitness at 5.5 years of age. This result may have occurred since VPA was not as strongly associated with motor fitness in the regression model analyses $(\beta=-0.21)$ (the faster time the better score) as with lower muscular strength $(\beta=$ 0.32) or cardiovascular fitness $(\beta=0.24)$.

The additional analyses showed that, despite of the baseline PA level, increasing high-intensity PA between 4.5 and 5.5 years of age was associated with improved body composition and muscular strength at follow-up. The results support our main findings, and additionally, emphasize the need to increase high-intensity PA in order to decrease \%FM and FMI already at young ages.

The strength of our study is that we used accurate and up-to-date methodology for measuring preschool aged children's body composition (15) and physical fitness (6) in a longitudinal 
design. Another strength is that we had accurate PA and SB data at baseline and at follow-up, enabling additional analyses to examine whether changes in PA and SB over the 12-month follow-up period were associated with corresponding changes in body composition and physical fitness. However, the study also has some limitations that need to be considered. Firstly, the sample size of the study is somewhat small since in order to avoid biased results we excluded the children who were in the intervention group. Nevertheless, the study was powered to detect weak associations and despite the relatively small sample size, the associations found were strong and consistent. Secondly, it is an observational study, and thus, causality cannot be determined. Finally, since we wanted to compare our results to our cross-sectional study, we used cut-points derived in 8-12-year-olds to assess SB, LPA, MPA and VPA. The cut-points for wrist-worn wGT3x-BT in preschool aged children (21) are only for SB and MVPA. It is also notable that in our previous study (22) we analysed accelerometer data using the cut-points and the VM percentiles, and the results were consistent. In addition, the findings of our previous crosssectional study have been recently confirmed by Collings et al. (9). Therefore, it is unlikely that the cut-points we used have affected our results.

The MINISTOP study is strengthened by the fact that the participants were recruited from a population-based sample. As reported previously (13), no major difference in the child's country of birth, sex or area of residence between the MINISTOP sample and the whole invited sample were found. Thus, it is unlikely that our study suffers from any severe selection bias at the recruitment level. Additionally, the participating parents' BMI were in accordance with the general population (37), and the children's body size and prevalence of overweight as well as intakes of fruits and vegetables, sweetened beverages and candy were comparable to Swedish national data $(27,31)$. The parents of participating children were slightly better educated than the 
general Swedish population (37), which may in turn limit generalizability of the results due to the association between high parental education and a higher performance in motor testing in preschoolers (1). However, in this context it is relevant to note that our associations remained after adjustment for parental education.

The public health and clinical significance of the findings also deserves some comments. Overall, we identified quite strong associations of PA with body composition and physical fitness. For instance, a 5-minute/day greater VPA at the age of 4.5 was associated with a higher FFMI ( $\beta=0.33)$, and with a better performance in the $20 \mathrm{~m}$ shuttle run $(\beta=0.24)$, standing long jump $(\beta=0.32)$ and $4 \times 10 \mathrm{~m}$ shuttle run tests $(\beta=-0.21)$ at 5.5 years of age. Hence, we believe that the identified associations are strong enough to have importance for public health and possibly also for clinical care. These findings emphasize a potential role of high-intensity PA in preschool aged children in supporting fat-free mass and physical fitness in the long-term. Therefore, games or structured PA that include short and high-intensity bursts, may be effective in increasing highintensity PA in this age group.

In conclusion, greater VPA and MVPA at the age of 4.5 were associated with higher FFMI and with better physical fitness at the 12-month follow-up. Greater VPA was also positively associated with BMI, and this finding reflected a higher fat-free mass (not fat mass). These observational results suggest that promoting high-intensity PA at young ages may have longterm effects by improving body composition and physical fitness, in particular muscular strength. 


\section{ACKNOWLEDGMENTS}

The authors thank the participating families as well as Eva Flinke Carlsson, Gunilla Hennermark, Birgitta Jensen, Ann-Sofie Risinger for help regarding recruitment and data collection, and Jani Raitanen for help with the layout of the figure. The results of the present study do not constitute endorsement by ACSM, and the results are presented clearly, honestly, and without fabrication, falsification, or inappropriate data manipulation.

Conflicts of Interest and Sources of Support: The MINISTOP project was funded by the Swedish Research Council (project no. 2012-2883, ML), the Swedish Research Council for Health, Working Life and Welfare (2012-0906, ML), Bo and Vera Axson Johnsons Foundation and Karolinska Institutet (ML). MHL was supported by a grant from Juho Vainio Foundation and from University of Jyvaskyla; PH was supported by a grant from Henning and Johan Throne-Holst Foundation; CDN was supported by a grant from the Swedish Nutrition Foundation; HH was supported by grants from the Swedish Society of Medicine and the County Council of Östergötland, Sweden; FBO and CC-S were supported by the Spanish Ministry of Economy and Competitiveness (grants RYC-2011-09011 and BES-2014-068829, respectively). None of the authors had a conflict of interest.

Authors contributions: ML is the Principal Investigator for the MINISTOP trial and designed this research together with all co-authors. JRR, FBO and CCS designed the fitness tests for the MINISTOP trial. CDN was responsible for data collection, JP was responsible for processing of the accelerometer data and $\mathrm{PH}$ for the statistical analyses and contributed to manuscript preparation. MHL was responsible for data analysis, and drafted the manuscript, which was subsequently reviewed by PH, CDN, HH, FBO, JRR, CCS, JP and ML. All authors approved the final version. 


\section{REFERENCES}

1. Bayer O, Bolte G, Morlock G, Rückinger S, von Kries R. GME-Study Group A simple assessment of physical activity is associated with obesity and motor fitness in pre-school children. Public Health Nutr. 2009; 12: 1242 -1247.

2. Bornstein DB, Beets MW, Byun W, McIver K. Accelerometer-derived physical activity levels of preschoolers: a meta-analysis. J Sci Med Sport. 2011; Nov;14(6):504-11.

3. Bürgi F, Meyer U, Granacher U, et al. Relationship of physical activity with motor skills, aerobic fitness and body fat in preschool children: a crosssectional and longitudinal study (Ballabeina). Int J Obes (Lond). 2011; Jul;35(7):937-44.

4. Butte NF, Puyau MR, Wilson TA, et al. Role of physical activity and sleep duration in growth and body composition of preschool-aged children. Obesity (Silver Spring). 2016; Jun;24(6):1328-35.

5. Cadenas-Sanchez C, Delisle C, Sanchez-Delgado G, et al. Prevalence of overweight/obesity and fitness levels in preschool children form the north compared to the south of Europe- an exploration with two countries. Pediatr Obes. 2016; Oct;11(5):403-10.

6. Cadenas-Sanchez C, Martinez-Tellez B, Sanchez-Delgado G, et al. Assessing physical fitness in preschool children: Feasibility, reliability and practical recommendations for the PREFIT battery. J Sci Med Sport. 2016; Nov;19(11):910-915. 
7. Chandler JL, Brazendale K, Beets MW, Mealing BA. Classification of physical activity intensities using a wrist-worn accelerometer in 8-12-year-old children. Pediatr Obes. 2015; Apr;11(2):120-7.

8. Cole TJ, Lobstein T. Extended international (IOTF) body mass index cut-offs for thinness, overweight and obesity. Pediatr Obes. 2012; Aug;7(4):284-94.

9. Collings PJ, Brage S, Bingham DD, et al. Physical Activity, Sedentary Time, and Fatness in a Biethnic Sample of Young Children. Med Sci Sports Exerc. 2017;49(5): 930-8.

10. Collings PJ, Brage S, Ridgway CL, et al. Physical activity intensity, sedentary time, and body composition in preschoolers. Am J Clin Nutr. 2013;97(5):1020-8.

11. Delisle C, Sandin S, Forsum E, et al. A web- and mobile phone-based intervention to prevent obesity in 4 year-olds (MINISTOP): a population-based randomized controlled trial. BMC public health. 2015; Feb 7;15:95.

12. Delisle Nyström C, Henriksson P, Alexandrou C, Löf M. The Tanita SC-240 to Assess Body Composition in Pre-School Children: An Evaluation against the Three Component Model. Nutrients. 2016; Jun 16;8(6). pii: E371.

13. Delisle Nyström C, Sandin S, Henriksson P, et al. Mobile-based intervention intended to stop obesity in pre-school children: The MINISTOP randomized controlled trial. Am J Clin Nutr. 
2017, in press, doi: 10.3945/ajcn.116.150995.

14. España-Romero V, Mitchell JA, Dowda M, O'Neill JR, Pate RR. Objectively measured sedentary time, physical activity and markers of body fat in preschool children. Pediatr Exerc. Sci 2013; Feb;25(1):154-63.

15. Fields DA, Allison DB. Air-displacement plethysmography pediatric option in 2-6 years old using the four-compartment model as a criterion method. Obesity. 2012; 20: 1732-1737.

16. Forsum E, Flinke Carlsson E, Henriksson H, Henriksson P, Löf M. Total body fat content versus BMI in 4-year-old healthy Swedish children. J Obes. 2013;2013:206715.

17. Henriksson P, Cadenas-Sanchez C, Leppänen MH, et al. Associations of Fat Mass and FatFree Mass with Physical Fitness in 4-Year-Old Children: Results from the MINISTOP Trial. Nutrients. 2016; Jul 30;8(8). pii: E473.

18. Jackson DM, Donaghy Z, Djafarian K, Reilly JJ. Validation of simple epidemiological or clinical methods for the measurement of body composition in young children. Iran $J$ Pediatr. 2014; Dec;24(6):685-91.

19. Jago R, Baranowski T, Baranowski JC, Thompson D, Greaves KA. BMI from 3-6 y of age is predicted by TV viewing and physical activity, not diet. Int J Obes (Lond). 2005; Jun;29(6):55764. 
20. Janz KF, Levy SM, Burns TL, Torner JC, Willing MC, Warren JJ. Fatness, physical activity, and television viewing in children during the adiposity rebound period: the Iowa Bone Development Study. Prev Med. 2002; Dec;35(6):563-71.

21. Johansson E, Larisch LM, Marcus C, Hagströmer M. Calibration and Validation of a Wristand Hip-Worn Actigraph Accelerometer in 4-Year-Old Children. PLoS One. 2016; Sep 12;11(9):e0162436.

22. Leppänen $\mathrm{MH}$, Nyström CD, Henriksson $\mathrm{P}$, et al. Physical activity intensity, sedentary behavior, body composition and physical fitness in 4-year-old children: results from the ministop trial. Int J Obes (Lond). 2016; Jul;40(7):1126-33.

23. Mekary RA, Willett WC, Hu FB, Ding EL. Isotemporal substitution paradigm for physical activity epidemiology and weight change. Am J Epidemiol. 2009; Aug 15;170(4):519-27.

24. Metcalf BS, Voss LD, Hosking J, Jeffery AN, Wilkin TJ. Physical activity at the government-recommended level and obesity-related health outcomes: a longitudinal study (Early Bird 37). Arch Dis Child. 2008; Sep;93(9):772-7.

25. Moore LL, Nguyen US, Rothman KJ, Cupples LA, Ellison RC. Preschool physical activity level and change in body fatness in young children. The Framingham Children's Study. Am J Epidemiol. 1995; Nov 1;142(9):982-8.

26. Nader PR, O'Brien M, Houts R, et al. National Institute of Child Health and Human 
Development Early Child Care Research Network. Identifying risk for obesity in early childhood. Pediatrics. 2006; Sep;118(3):e594-601.

27. National Food Agency of Sweden. Riksmaten, 2003. Available at: http://www.slv.se/ (accessed 5 April 2017).

28. Ortega FB, Cadenas-Sánchez C, Sánchez-Delgado G, et al. Systematic review and proposal of a field-based physical fitness-test battery in preschool children: the PREFIT battery. Sports Med. 2015; Apr;45(4):533-55.

29. Ortega FB, Ruiz JR, Castillo MJ, Sjostrom M. Physical fitness in childhood and adolescence: a powerful marker of health. Int J Obes (Lond). 2008;32(1):1-11.

30. Padilla-Moledo C, Ruiz JR, Ortega FB, Mora J, Castro-Piñero J. Associations of muscular fitness with psychological positive health, health complaints, and health risk behaviors in Spanish children and adolescents. J Strength Cond Res. 2012; Jan;26(1):167-73.

31. Public Health Agency of Sweden. Health in Sweden. 2014. Available at: http:// www.folkhalsomyndigheten.se/ (accessed 23 October 2016).

32. Pulgarón ER. Childhood obesity: a review of increased risk for physical and psychological comorbidities. Clin Ther. 2013; Jan;35(1):A18-32.

33. Reilly JJ, Bonataki M, Leary SD, et al. Progression from childhood overweight to adolescent 
obesity in a large contemporary cohort. Int J Pediatr Obes. 2011; Jun;6(2-2):e138-43.

34. Ruiz JR, Castro-Piñero J, Artero EG, et al. Predictive validity of health-related fitness in youth: a systematic review. Br J Sports Med. 2009; Dec;43(12):909-23.

35. Sadeh A, Lavie P, Scher A, Tirosh E, Epstein R. Actigraphic home-monitoring sleepdisturbed and control infants and young children: a new method for pediatric assessment of sleep-wake patterns. Pediatrics. 1991; 87: $494-499$.

36. Sadeh A, Sharkey KM, Carskadon MA. Activity-based sleep-wake identification: an empirical test of methodological issues. Sleep. 1994; 17: 201 -207

37. Statistics Sweden. Förändringar i Undersökningarna av levnadsförhållandena. 2010. Available at: http://www.scb.se/ (accessed 5 April 2017).

38. Vale SM, Santos RM, da Cruz Soares-Miranda LM, Moreira CM, Ruiz JR, Mota JA. Objectively measured physical activity and body mass index in preschool children. Int J Pediatr. 2010; 2010. pii: 479439.

39. van Hees VT, Renström F, Wright A, et al. Estimation of daily energy expenditure in pregnant and non-pregnant women using a wristworn tri-axial accelerometer. PLoS One. 2011; 6: e22922.

40. World Health Organization. World Health Statistics. 2015. Internet: http://apps.who.int/ (accessed 15 October 2016). 


\section{Supplemental Digital Content (SDC)}

Supplemental Table 1.docx-Associations of change in accelerometer-derived physical activity intensities (per 5-min change) with change in body composition and physical fitness between baseline at 4.5 years of age and the 12-month follow-up

\section{Figure legends}

Figure 1. Isotemporal substitution analysis showing the associations of replacing 5-minute/day of one PA type with 5-minute/day of another PA type at baseline with body composition and physical fitness at the 12-month follow-up. The results are presented as beta-coefficients with $95 \%$ confidence intervals. $\mathrm{N}=132-137$.

Abbreviations: BMI, body mass index; FFMI, fat-free mass index; SB, sedentary behavior; LPA, light-intensity physical activity; MPA, moderate-intensity physical activity; VPA, vigorousintensity physical activity. PA and SB are classified according to Chandler et al. (7). All models are adjusted for child's sex, age at measurement, and awake wearing time. 

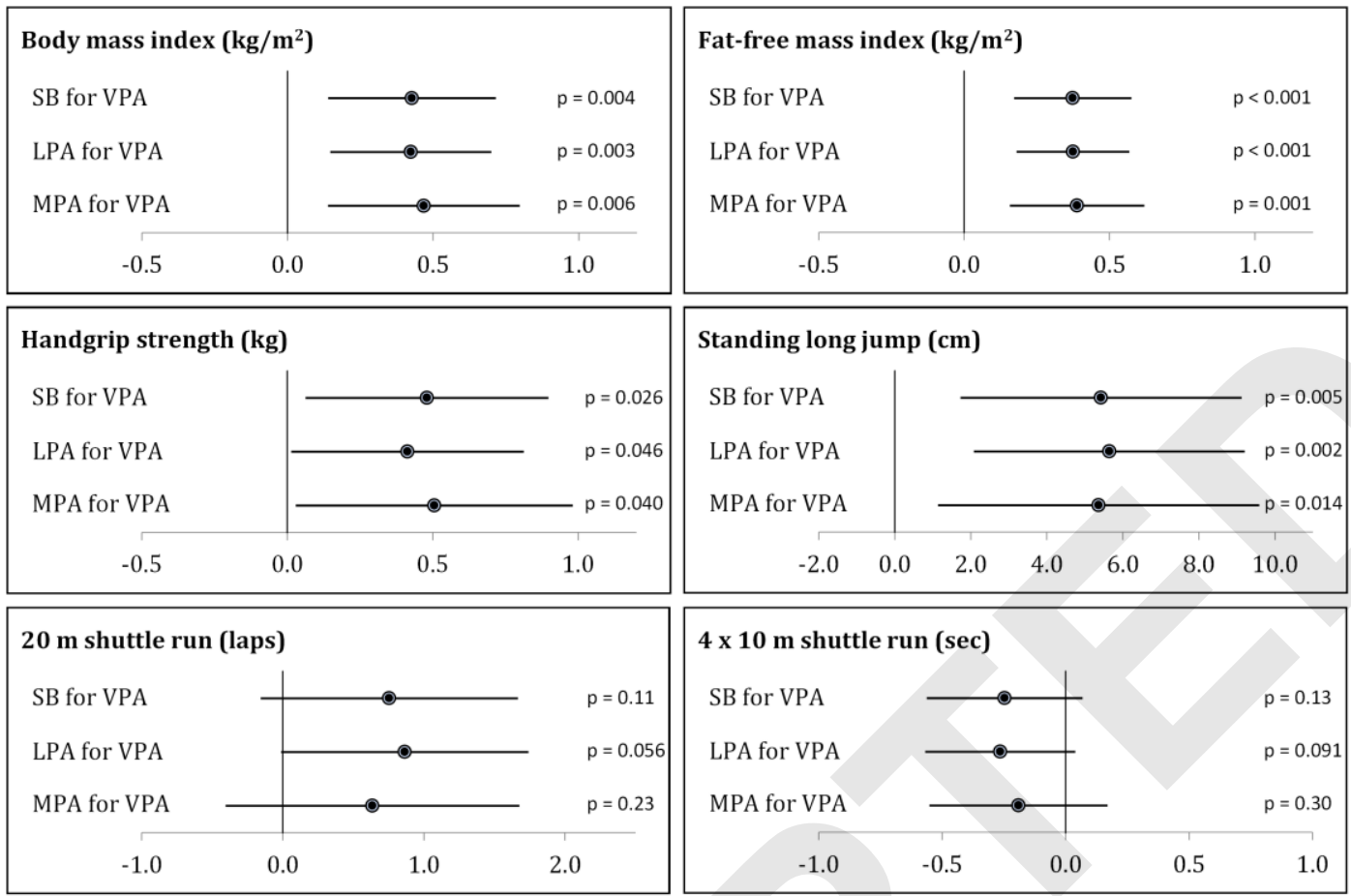

Associations $(95 \% \mathrm{CI})$ per $5 \mathrm{~min} /$ day reallocation 
Table 1. Characteristics of participating children at baseline and at 12-month follow-up.

\begin{tabular}{|c|c|c|c|c|c|c|c|c|}
\hline & \multicolumn{4}{|c|}{ Baseline } & \multicolumn{4}{|c|}{ 12-month follow-up } \\
\hline & $\begin{array}{c}\text { All } \\
(\mathbf{n}=138)\end{array}$ & $\begin{array}{c}\text { Boys } \\
(n=73)\end{array}$ & $\begin{array}{c}\text { Girls } \\
(n=65)\end{array}$ & $\begin{array}{c}\text { P-sex } \\
\text { difference }\end{array}$ & $\begin{array}{c}\text { All } \\
(n=138)\end{array}$ & $\begin{array}{c}\text { Boys } \\
(n=73)\end{array}$ & $\begin{array}{c}\text { Girls } \\
(n=65)\end{array}$ & $\begin{array}{c}\text { P-sex } \\
\text { difference }\end{array}$ \\
\hline $\operatorname{Age}(y)$ & $4.48 \pm 0.15$ & $4.49 \pm 0.15$ & $4.46 \pm 0.16$ & 0.35 & $5.55 \pm 0.18$ & $5.56 \pm 0.18$ & $5.54 \pm 0.17$ & 0.36 \\
\hline Height (cm) & $108 \pm 4.35$ & $108 \pm 4.48$ & $107 \pm 4.10$ & 0.057 & $115 \pm 4.86$ & $116 \pm 4.76$ & $114 \pm 4.84$ & 0.035 \\
\hline Weight (kg) & $18.2 \pm 2.35$ & $18.6 \pm 2.48$ & $17.6 \pm 2.09$ & 0.013 & $20.5 \pm 2.97$ & $21.0 \pm 3.09$ & $20.0 \pm 2.76$ & 0.041 \\
\hline $\operatorname{BMI}\left(\mathrm{kg} / \mathrm{m}^{2}\right)^{1}$ & $15.6 \pm 1.22$ & $15.8 \pm 1.25$ & $15.4 \pm 1.15$ & 0.048 & $15.4 \pm 1.34$ & $15.5 \pm 1.41$ & $15.2 \pm 1.24$ & 0.19 \\
\hline Overweight/obese (\%) & 7.2 & 8.2 & 6.2 & 0.87 & 6.5 & 6.9 & 6.1 & 0.87 \\
\hline FFMI $\left(\mathrm{kg} / \mathrm{m}^{2}\right)$ & $11.6 \pm 0.95$ & $11.9 \pm 0.96$ & $11.3 \pm 0.84$ & $<0.001$ & $12.2 \pm 1.04$ & $12.5 \pm 1.09$ & $11.8 \pm 0.83$ & $<0.001$ \\
\hline FM $(\%)$ & $25.7 \pm 4.41$ & $24.8 \pm 3.75$ & $26.8 \pm 4.89$ & 0.007 & $20.8 \pm 4.83$ & $19.3 \pm 4.49$ & $22.5 \pm 4.67$ & $<0.001$ \\
\hline FMI $\left(\mathrm{kg} / \mathrm{m}^{2}\right)$ & $4.04 \pm 0.84$ & $3.94 \pm 0.74$ & $4.16 \pm 0.94$ & 0.12 & $3.22 \pm 0.92$ & $3.02 \pm 0.90$ & $3.45 \pm 0.90$ & 0.006 \\
\hline \multicolumn{9}{|l|}{$\begin{array}{l}\text { Physical activity and sedentary } \\
\text { behaviour }\end{array}$} \\
\hline Valid days $^{2}$ & $6.57 \pm 0.90$ & $6.59 \pm 0.85$ & $6.54 \pm 0.97$ & 0.74 & $6.47 \pm 1.18$ & $6.49 \pm 1.26$ & $6.45 \pm 1.10$ & 0.84 \\
\hline Awake wear time (min/day) & $844 \pm 58.5$ & $836 \pm 67.3$ & $853 \pm 45.4$ & 0.083 & $862 \pm 60.7$ & $861 \pm 60.4$ & $864 \pm 61.5$ & 0.78 \\
\hline SB $(\min / \text { day })^{3}$ & $481 \pm 50.2$ & $475 \pm 48.4$ & $489 \pm 51.6$ & 0.11 & $486 \pm 58.9$ & $487 \pm 57.9$ & $486 \pm 60.5$ & 0.92 \\
\hline Light PA (min/day $)^{3}$ & $261 \pm 28.4$ & $259 \pm 31.6$ & $262 \pm 24.5$ & 0.50 & $259 \pm 29.6$ & $258 \pm 29.2$ & $261 \pm 30.2$ & 0.52 \\
\hline Moderate PA (min/day) ${ }^{3}$ & $94.6 \pm 22.6$ & $93.4 \pm 24.5$ & $96.0 \pm 20.3$ & 0.50 & $105 \pm 22.0$ & $104 \pm 22.8$ & $106 \pm 21.2$ & 0.49 \\
\hline Vigorous PA (min/day $)^{3}$ & $7.16 \pm 4.69$ & $8.28 \pm 5.60$ & $5.89 \pm 2.94$ & 0.002 & $11.9 \pm 7.19$ & $13.2 \pm 8.45$ & $10.4 \pm 5.00$ & 0.024 \\
\hline Moderate-to-vigorous PA $(\mathrm{min} / \mathrm{day})^{3}$ & $101 \pm 24.9$ & $101 \pm 27.9$ & $102 \pm 21.4$ & 0.97 & $116 \pm 25.9$ & $116 \pm 28.3$ & $116 \pm 23.1$ & 0.98 \\
\hline \multicolumn{9}{|l|}{ Physical fitness tests } \\
\hline 20 m shuttle run (laps) & $5.93 \pm 2.57$ & $6.00 \pm 2.46$ & $5.86 \pm 2.70$ & 0.75 & $10.0 \pm 4.07$ & $9.86 \pm 3.78$ & $10.2 \pm 4.41$ & 0.66 \\
\hline Handgrip strength (kg) & $6.50 \pm 1.66$ & $6.87 \pm 1.85$ & $6.07 \pm 1.29$ & 0.004 & $8.96 \pm 2.03$ & $9.60 \pm 2.02$ & $8.25 \pm 1.80$ & $<0.001$ \\
\hline Standing long jump (cm) & $72.1 \pm 15.1$ & $73.0 \pm 14.8$ & $71.1 \pm 15.4$ & 0.46 & $94.9 \pm 17.3$ & $96.6 \pm 18.5$ & $93.0 \pm 15.8$ & 0.23 \\
\hline $4 \times 10$ m shuttle run $(\mathrm{sec})^{4}$ & $18.4 \pm 1.98$ & $18.4 \pm 2.11$ & $18.5 \pm 1.84$ & 0.73 & $16.2 \pm 1.46$ & $16.2 \pm 1.38$ & $16.2 \pm 1.55$ & 0.79 \\
\hline
\end{tabular}

Data are given as mean \pm SD or $\mathrm{n} \pm \%$. BMI, body mass index; FFMI, fat-free mass index; FM, fat mass; FMI, fat mass index; SB, Sedentary behaviour; PA, physical activity

${ }_{1}^{1}$ According to Cole \& Lobstein (8).

${ }^{2}$ Defined as $\geq 600$ minutes of nonsleeping data (10).

${ }^{3}$ According to Chandler et al. (7).

${ }^{4}$ The lower the score (in seconds), the higher the performance.

Sex comparisons were made by using t-test, except chi-square test for categorized variables (overweight/obese). $\mathrm{P}<0.05$ was considered statistically significant. 
Table 2. Associations of accelerometer-derived physical activity intensities ${ }^{1}$ at baseline at 4.5 years of age with body composition and physical fitness at 12-months follow-up per 5-min increase in physical activity intensities. The unstandardized regression coefficient (b) with its $95 \%$ confidence interval (CI), the standardized regression coefficient $(\beta)$ and the $P$ value are given for each association.

\begin{tabular}{|c|c|c|c|c|c|c|}
\hline & \multicolumn{3}{|c|}{ Unadjusted } & \multicolumn{3}{|c|}{ Adjusted $^{2}$} \\
\hline & $\mathrm{b}(95 \% \mathrm{CI})$ & $\beta$ & $P$ value & $\mathrm{b}(95 \% \mathrm{CI})$ & $\beta$ & $\mathrm{P}$ value \\
\hline \multicolumn{7}{|c|}{ Measures of body composition } \\
\hline \multicolumn{7}{|c|}{$\mathrm{BMI}\left(\mathrm{kg} / \mathrm{m}^{2}\right), \mathrm{n}=138$} \\
\hline SB & $0.00(-0.02$ to 0.02$)$ & 0.00 & 0.99 & $0.02(-0.02$ to 0.05$)$ & 0.13 & 0.30 \\
\hline MPA & $0.00(-0.05$ to 0.05$)$ & 0.00 & 0.96 & $-0.04(-0.10$ to 0.02$)$ & -0.13 & 0.19 \\
\hline VPA & $0.35(0.11$ to 0.58$)$ & 0.24 & 0.004 & $0.39(0.12$ to 0.65$)$ & 0.27 & 0.005 \\
\hline MVPA & $0.01(-0.03$ to 0.06$)$ & 0.05 & 0.56 & $0.05(-0.04$ to 0.14$)$ & 0.19 & 0.29 \\
\hline \multicolumn{7}{|c|}{ FFMI $\left(\mathrm{kg} / \mathrm{m}^{2}\right), \mathrm{n}=137$} \\
\hline SB & $-0.01(-0.02$ to 0.01$)$ & -0.05 & 0.54 & $0.01(-0.02$ to 0.03$)$ & 0.07 & 0.50 \\
\hline MPA & $0.03(-0.01$ to 0.07$)$ & 0.14 & 0.11 & $-0.02(-0.06$ to 0.03$)$ & -0.07 & 0.45 \\
\hline VPA & $0.44(0.27$ to 0.62$)$ & 0.40 & $<0.001$ & $0.36(0.18$ to 0.55$)$ & 0.33 & $<0.001$ \\
\hline MVPA & 0.04 (0.01 to 0.08$)$ & 0.20 & 0.019 & $0.07(0.00$ to 0.13$)$ & 0.32 & 0.044 \\
\hline \multicolumn{7}{|c|}{$\mathrm{FM}(\%), \mathrm{n}=137$} \\
\hline SB & $0.03(-0.05$ to 0.11$)$ & 0.06 & 0.46 & $0.05(-0.05$ to 0.16$)$ & 0.11 & 0.32 \\
\hline MPA & $-0.21(-0.39$ to -0.03$)$ & -0.20 & 0.022 & $-0.12(-0.32$ to 0.08$)$ & -0.11 & 0.22 \\
\hline VPA & $-1.01(-1.87$ to -0.16$)$ & -0.20 & 0.021 & $-0.24(-1.11$ to 0.62$)$ & -0.05 & 0.58 \\
\hline MVPA & $-0.21(-0.37$ to -0.05$)$ & -0.21 & 0.013 & $-0.13(-0.42$ to 0.16$)$ & -0.14 & 0.37 \\
\hline \multicolumn{7}{|c|}{ FMI $\left(\mathrm{kg} / \mathrm{m}^{2}\right), \mathrm{n}=137$} \\
\hline SB & $0.01(-0.01$ to 0.02$)$ & 0.06 & 0.52 & $0.01(-0.01$ to 0.03$)$ & 0.01 & 0.34 \\
\hline MPA & $-0.03(-0.07$ to 0.00$)$ & -0.16 & 0.067 & $-0.03(-0.07$ to 0.01$)$ & -0.13 & 0.20 \\
\hline VPA & $-0.10(-0.26$ to 0.07$)$ & -0.10 & 0.24 & $0.02(-0.15$ to 0.20$)$ & 0.02 & 0.79 \\
\hline MVPA & $-0.03(-0.06$ to 0.00$)$ & -0.16 & 0.061 & $-0.02(-0.08$ to 0.04$)$ & -0.09 & 0.58 \\
\hline \multicolumn{7}{|c|}{ Measures of physical fitness } \\
\hline \multicolumn{7}{|c|}{ Cardiorespiratory fitness: $20 \mathrm{~m}$ shuttle run (laps), $\mathrm{n}=133$} \\
\hline SB & $-0.02(-0.09$ to 0.05$)$ & -0.06 & 0.49 & $0.01(-0.10$ to 0.10$)$ & 0.01 & 0.93 \\
\hline MPA & $0.14(-0.01$ to 0.30$)$ & 0.16 & 0.067 & $0.06(-0.13$ to 0.24$)$ & 0.06 & 0.55 \\
\hline VPA & $0.96(0.21$ to 1.70$)$ & 0.22 & 0.012 & $1.05(0.20$ to 1.89$)$ & 0.24 & 0.016 \\
\hline MVPA & $0.15(0.01$ to 0.29$)$ & 0.18 & 0.034 & $0.36(0.08$ to 0.64$)$ & 0.44 & 0.014 \\
\hline \multicolumn{7}{|c|}{ Upper muscular strength: handgrip strength $(\mathrm{kg}), \mathrm{n}=137$} \\
\hline SB & $-0.04(-0.08$ to -0.01$)$ & -0.21 & 0.016 & $-0.03(-0.07$ to 0.02$)$ & -0.12 & 0.29 \\
\hline
\end{tabular}




\begin{tabular}{|c|c|c|c|c|c|c|}
\hline MPA & $0.03(-0.05$ to 0.10$)$ & 0.06 & 0.51 & $0.01(-0.07$ to 0.10$)$ & 0.03 & 0.76 \\
\hline VPA & $0.55(0.20$ to 0.91$)$ & 0.26 & 0.002 & $0.34(-0.04$ to 0.72$)$ & 0.16 & 0.083 \\
\hline MVPA & $0.04(-0.03$ to 0.11$)$ & 0.10 & 0.25 & $0.01(-0.12$ to 0.14$)$ & 0.03 & 0.88 \\
\hline \multicolumn{7}{|c|}{ Lower muscular strength: standing long jump $(\mathrm{cm}), \mathrm{n}=136$} \\
\hline SB & $-0.18(-0.47$ to 0.12$)$ & -0.10 & 0.24 & $0.09(-0.32$ to 0.50$)$ & 0.05 & 0.67 \\
\hline MPA & $0.45(-0.20$ to 1.10$)$ & 0.12 & 0.18 & $-0.06(-0.82$ to 0.70$)$ & -0.02 & 0.87 \\
\hline VPA & $5.72(2.74$ to 8.71$)$ & 0.31 & $<0.001$ & $5.86(2.45$ to 9.26$)$ & 0.32 & 0.001 \\
\hline MVPA & $0.57(-0.02$ to 1.15$)$ & 0.16 & 0.056 & $1.37(0.19$ to 2.54$)$ & 0.40 & $\mathbf{0 . 0 2 3}$ \\
\hline \multicolumn{7}{|c|}{ Motor fitness: $4 \times 10 \mathrm{~m}$ shuttle run $(\mathrm{s}), \mathrm{n}=136$} \\
\hline SB & $0.02(-0.002$ to 0.05$)$ & 0.16 & 0.066 & $0.02(-0.02$ to 0.05$)$ & 0.02 & 0.38 \\
\hline MPA & $-0.06(-0.12$ to -0.01$)$ & 0.03 & 0.021 & $-0.05(-0.11$ to 0.02$)$ & -0.14 & 0.17 \\
\hline VPA & $-0.36(-0.62$ to -0.10$)$ & -0.23 & 0.006 & $-0.32(-0.61$ to -0.03$)$ & -0.21 & 0.031 \\
\hline MVPA & $-0.06(-0.11$ to -0.02$)$ & -0.22 & 0.010 & $-0.11(-0.21$ to -0.01$)$ & -0.39 & 0.026 \\
\hline
\end{tabular}

Abbreviations: BMI, body mass index; FFMI, fat-free mass index; FM, fat mass; FMI, fat mass index; SB, sedentary behavior; MPA, moderate-intensity physical activity; VPA, vigorous-intensity physical activity; MVPA, moderate-to-vigorous physical activity.

${ }^{1}$ According to Chandler et al. (7).

${ }^{2}$ Adjusted for child's sex, age at measurement, and awake wearing time, and additionally, models with SB or MPA as exposures were adjusted for VPA, while models with VPA or MVPA were adjusted for SB. 
Supplemental Table 1. Associations of change in accelerometer-derived physical activity intensities ${ }^{1}$ (per 5 -min change) with change in body composition and physical fitness between baseline at 4.5 years of age and the 12-month follow-up. The unstandardized regression coefficient (b) with its $95 \%$ confidence interval $(\mathrm{CI})$, the standardized regression coefficient $(\beta)$ and the $P$ value are given for each association.

\begin{tabular}{|c|c|c|c|c|c|c|}
\hline & \multicolumn{3}{|c|}{ Unadjusted } & \multicolumn{3}{|c|}{ Adjusted $^{2}$} \\
\hline & $\mathrm{b}(95 \% \mathrm{CI})$ & $\beta$ & $\mathrm{P}$ value & $\mathrm{b}(95 \% \mathrm{CI})$ & $\beta$ & $P$ value \\
\hline \multicolumn{7}{|c|}{ Measures of body composition } \\
\hline \multicolumn{7}{|c|}{ Change in BMI $\left(\mathrm{kg} / \mathrm{m}^{2}\right), \mathrm{n}=132$} \\
\hline Change in SB & $-0.00(-0.01$ to 0.01$)$ & -0.03 & 0.75 & $0.00(-0.01$ to 0.01$)$ & 0.00 & 0.99 \\
\hline Change in MPA & $0.01(-0.01$ to 0.03$)$ & 0.06 & 0.53 & $-0.00(-0.03$ to 0.03$)$ & -0.02 & 0.86 \\
\hline Change in VPA & $0.02(-0.05$ to 0.10$)$ & 0.05 & 0.56 & $0.03(-0.06$ to 0.11$)$ & 0.06 & 0.53 \\
\hline Change in MVPA & $0.01(-0.01$ to 0.03$)$ & 0.06 & 0.48 & $0.01(-0.02$ to 0.05$)$ & 0.14 & 0.40 \\
\hline \multicolumn{7}{|c|}{ Change in FFMI $\left(\mathrm{kg} / \mathrm{m}^{2}\right), \mathrm{n}=130$} \\
\hline Change in SB & $-0.01(-0.02$ to 0.00$)$ & -0.15 & 0.088 & $-0.01(-0.02$ to 0.01$)$ & -0.13 & 0.29 \\
\hline Change in MPA & $0.01(-0.01$ to 0.04$)$ & 0.10 & 0.28 & $0.02(-0.01$ to 0.05$)$ & 0.14 & 0.20 \\
\hline Change in VPA & $0.10(0.01$ to 0.19$)$ & 0.19 & 0.031 & $0.07(-0.02$ to 0.16$)$ & 0.14 & 0.11 \\
\hline Change in MVPA & $0.02(-0.01$ to 0.04$)$ & 0.13 & 0.14 & $0.04(0.00$ to 0.08$)$ & 0.32 & 0.037 \\
\hline \multicolumn{7}{|c|}{ Change in FM (\%), n=130 } \\
\hline Change in SB & $0.05(-0.01$ to 0.10$)$ & 0.15 & 0.092 & $0.03(-0.04$ to 0.10$)$ & 0.10 & 0.39 \\
\hline Change in MPA & $-0.03(-0.16$ to 0.11$)$ & -0.04 & 0.69 & $-0.07(-0.23$ to 0.09$)$ & -0.09 & 0.38 \\
\hline Change in VPA & $-0.53(-1.04$ to -0.03$)$ & -0.18 & 0.040 & $-0.72(-1.21$ to -0.23$)$ & -0.25 & 0.004 \\
\hline Change in MVPA & $-0.05(-0.17$ to 0.07$)$ & -0.07 & 0.40 & $-0.22(-0.42$ to -0.02$)$ & -0.32 & 0.031 \\
\hline \multicolumn{7}{|c|}{ Change in FMI $\left(\mathrm{kg} / \mathrm{m}^{2}\right), \mathrm{n}=130$} \\
\hline Change in SB & $0.01(-0.00$ to 0.02$)$ & 0.14 & 0.12 & $0.01(-0.01$ to 0.02$)$ & 0.14 & 0.27 \\
\hline Change in MPA & $-0.01(-0.03$ to 0.02$)$ & -0.05 & 0.60 & $-0.02(-0.04$ to 0.01$)$ & -0.11 & 0.32 \\
\hline Change in VPA & $-0.08(-0.16$ to 0.01$)$ & -0.15 & 0.086 & $-0.09(-0.18$ to -0.00$)$ & -0.18 & 0.048 \\
\hline Change in MVPA & $-0.01(-0.03$ to 0.01$)$ & -0.08 & 0.38 & $-0.03(-0.06$ to 0.01$)$ & -0.22 & 0.15 \\
\hline \multirow{2}{*}{\multicolumn{7}{|c|}{$\begin{array}{l}\text { Measures of physical fitness } \\
\text { Change in cardiorespiratory fitness: } 20 \mathrm{~m} \text { shuttle run (laps), } \mathrm{n}=123\end{array}$}} \\
\hline & & & & & & \\
\hline Change in SB & $0.00(-0.06$ to 0.06$)$ & 0.01 & 0.92 & $0.03(-0.07$ to 0.12$)$ & 0.08 & 0.60 \\
\hline Change in MPA & $-0.07(-0.22$ to 0.09$)$ & -0.08 & 0.38 & $-0.15(-0.35$ to 0.06$)$ & -0.17 & 0.16 \\
\hline Change in VPA & $0.22(-0.35$ to 0.78$)$ & 0.07 & 0.45 & $0.36(-0.25$ to 0.97$)$ & 0.11 & 0.25 \\
\hline Change in MVPA & $-0.04(-0.18$ to 0.10$)$ & -0.05 & 0.55 & $-0.08(-0.33$ to 0.16$)$ & -0.11 & 0.50 \\
\hline
\end{tabular}


Change in upper muscular strength: handgrip strength $(\mathrm{kg}), \mathrm{n}=130$

Change in SB

Change in MPA

Change in VPA

Change in MVPA

Change in lower muscul

\begin{abstract}
$-0.00(-0.03$ to 0.02$)$
\end{abstract}
$0.01(-0.05$ to 0.07$)$

0.24 (0.01 to 0.47$)$

0.02 (-0.03 to 0.08$)$
$-0.03$

0.03

0.18

0.07

ng long jump $(\mathrm{cm}), \mathrm{n}=130$

Change in SB

Change in MPA

Change in VPA

Change in MVPA$$
-0.03(-0.27 \text { to } 0.22)
$$$$
-0.21 \text { ( }-0.82 \text { to } 0.40)
$$

$-0.02$

$-0.06$

1.38 ( -0.96 to 3.71$)$

0.10 $-0.09(-0.64$ to 0.45$)$

$-0.03$
0.73

0.71

$\mathbf{0 . 0 4 3}$

0.43

$(\mathrm{s}), \mathrm{n}=130$

Change in SB

Change in MPA

Change in VPA

Change in MVPA
$-0.01(-0.03$ to 0.02$)$

$0.04(-0.03$ to 0.10$)$

$-0.02(-0.29$ to 0.25$)$

$0.03(-0.04$ to 0.09$)$
$-0.03 \quad 0.73$

$0.09 \quad 0.32$

$\begin{array}{ll}-0.01 & 0.89\end{array}$

$0.08 \quad 0.39$
$0.00(-0.03$ to 0.04$)$

0.01

$-0.04$

0.20

0.26 (0.03 to 0.50$)$

$0.07(-0.03$ to 0.16$)$

0.22

$0.15(-0.21$ to 0.51$)$

$-0.37(-1.17$ to 0.42$)$

0.11

$-0.11$

0.19

2.51 (0.21 to 4.80$)$

0.46 (-0.51 to 1.44$)$

0.15

$-0.01(-0.04$ to 0.02$)$

$0.02(-0.05$ to 0.09$)$

$-0.07$

$-0.16(-0.37$ to 0.04$)$

-0.03 (-0.11 to 0.06$)$
$-0.01(-0.09$ to 0.07$)$

0.94

0.75

$\mathbf{0 . 0 3 0}$

0.18

0.42

0.35

$\mathbf{0 . 0 3 3}$

0.35

Abbreviations: BMI, body mass index; FFMI, fat-free mass index; FM, fat mass; FMI, fat mass index; SB, sedentary behavior; MPA, moderate-intensity physical activity; VPA, vigorous-intensity physical activity; MVPA, moderate-to-vigorous physical activity.

${ }_{1}$ According to Chandler et al. (7).

${ }^{2}$ Adjusted for child's sex, age at measurement, awake wearing time at both time points, the baseline value of the outcome, and additionally, models with change in SB or MPA as exposures were adjusted for change in VPA, while models with change in VPA or MVPA were adjusted for change in SB. 